\title{
João Mendes Júnior, mestre de processo.
}

\section{Gabriel de Rezende Filho}

Catedrático de Direito Judiciário Civil na Faculdade de Direito da Universidade de São Paulo.

Nesta época que atravessamos, de tão marcado utilitarismo, assoberbados pela luta de todos os dias, quando tempo não nos sobra para repousar e poder voltar atrás, evocando as horas felizes de nossa juventude, a sessão de hoje representa, sem dúvida, um momento de pausa, permitindo-nos volver os olhos do espírito para a nossa gloriosa Faculdade, a Academia de outros tempos, com seus mestres a ensinarem no vetusto casarão de São Francisco, dentre os quais, como estrela de primeira grandeza, pelas suas qualidades intelectuais e morais, surgia, resplandecente e inolvidável, a figura de João Mendes Júnior.

O melhor de nossa vida è o passado, são aquêles dias felizes e descuidados de época já tão distante, cheia de recordações, quando nos animava sadio otimismo e não éramos ainda sacudidos pelas dificuldades da vida pública, que nos iria trazer desilusões e, por vêzes, um certo desencorajamento ante a rudeza das tarefas e a crua realidade das coisas.

Sentimos, por isso, transcorridos — aí de nós — oito lustros de nossa formatura, sentimos uma profunda saudade dos tempos acadêmicos, daquela quadra tranqüila de estudos e brincos juvenis, quase intraduzivel em palavras, já que para tanto nos faltam engenho e arte.

E nem porque regressamos depois à Casa comum, arrastados pela fôrça irresistível do destino, alcançando, com 
grande esfôrço, a cátedra, seguindo, assim, a nobre carreira de nossos antepassados, e nem porque aqui vivemos há tanto tempo, dedicados de corpo e alma à nossa missão de professor, podemos deixar de nos comover intensamente quando nos é dado o ensêjo de rememorar as glórias passadas e os eminentes vultos que por esta Academia passaram.

E na evocação que o nosso espírito vai fazendo, tudo como que se aclara e ressurge, e as imagens vão avultando e emergindo dêsse passado, dando-nos a sensação de que o presente se une ao passado e prepara o futuro para as novas gerações.

São os mestres de outros tempos, todos êles desaparecidos, que vamos tirando do fundo de nossa memória, grandes sombras da velha Faculdade, figuras imponentes de época longínqua, que passou definitivamente.

Dentre êles, nunca nos esquecemos de João Mendes Júnior.

Com aquêle seu ar abstrato, como que alheado das coisas terrenas, tipo de asceta, com a face macerada pelas vigílias do estudo, João Mendes Júnior era o mestre exímio, venerado por todos, respeitado pela vastidão e segurança de seus conhecimentos filosóficos e jurídicos, amado pela doçura e fidalguia de suas maneiras, impondo-se como um dos luzeiros mais expressivos da Congregação de então.

Nâo foi, todavia, o nosso professor mais profícuo, mas isso se devia não apenas à doença pertinaz que, ao nosso tempo, o afastava da cátedra por longos períodos, como principalmente à deficiência do curso de Direito Processual, o qual, pela lei de ensino, compreendia apenas o 5..$^{\circ}$ ano, tornando, assim, rudimentar e incompleto o estudo de tão árdua e importante disciplina.

No entanto, pela sua impressionante figura e pela autoridade de seus ensinamentos, João Mendes Júnior era um 


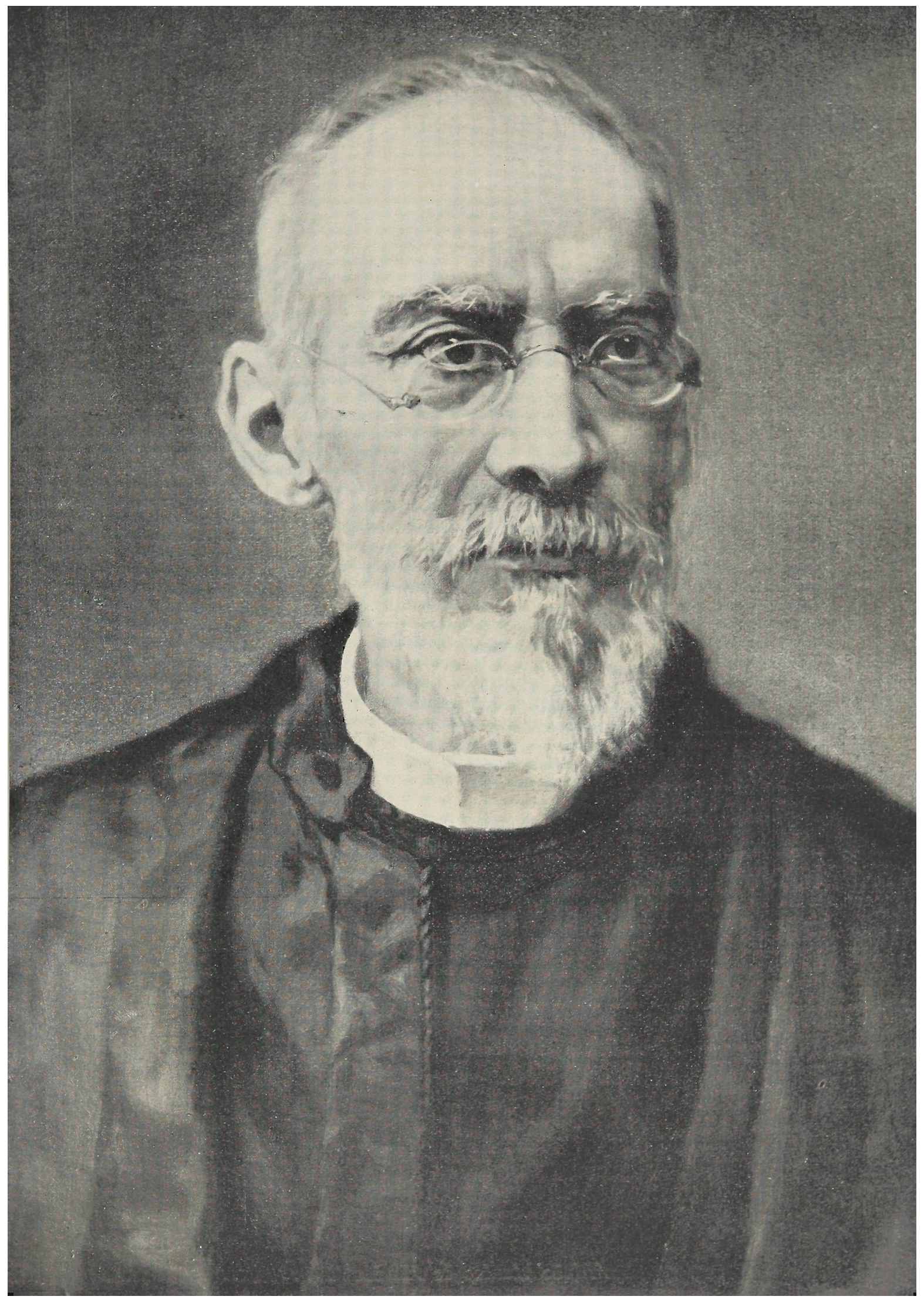


Prof. Joc̃o Mendes de Almeid 
autêntico mestre e, ainda hoje, todos os seus discipulos dêle se recordam com profunda saudade.

Proclamada a independência do Brasil, continuaram ainda a vigorar entre nós as Ordenações Filipinas, de acôrdo com o decreto da Assembléia Constituinte, de 20 de outubro de 1823, até que fôssem elaborados os códigos pelos quais dever-se-ia reger o Brasil.

Outorgada por Pedro $1 .^{\circ}$ a Carta Constitucional de 1824, urgia completar os princípios gerais na mesma consignados, princípios garantidores da liberdade, da segurança individual e da propriedade, com leis processuais adequadas, que com os mesmos tão íntima conexão mantêm.

O que nos legara Portugal era, afinal, uma legislação que não podia mais acomodar-se ao nosso país, ditada, como fôra, por necessidades de outras épocas, com um espirito retrógado, exigindo as condiçôes e os anseios dos brasileiros modificações legislativas melhor ajustadas ao nosso meio.

Uma decisão da Regência, em 1831, punha em evidência o lamentável estado da administração da justiça, dizendo que contra esta erguia-se "um geral clamor público, em grande parte devido à minuciosidade de um processo que tantos recursos of erecia às trapaças dos litigantes."

Surgiu, afinal, o famoso regulamento comercial 737, de 25 de novembro de 1850 , sem dúvida alguma um verdadeiro monumento, que atesta o alto padrão da cultura jurídica dos homens do Império, talvez a obra legislativa brasileira mais admirável em todos os tempos, segundo a consagração geral dos nossos maiores juristas.

Pela distribuição da matéria, pela precisão da linguagem, pela simplificação dos atos processuais, pela redução dos prazos, por uma melhor organização dos recursos, o 
regulamento 737 marcou sem dúvida uma fase de progresso em nosso direito processual.

Mas, êste regulamento aplicava-se apenas às causas comerciais, e não se destinava a reger o processo civil.

As causas cíveis continuaram a ser disciplinadas pelas vetustas Ordenações Portuguêsas, acrescidas de leis estravagantes, alvarás, assentos e cartas régias, consolidadas em 1876 pelo Conselheiro Ribas, com aprovação da resolução imperial de 28 de dezembro daquele ano.

Na primeira metade do século 19 , surgiu a figura de José Antônio Pimenta Bueno, visconde e depois marquês de São Vicente, que aos nossos anais políticos e às letras jurídicas legou uma notável obra, que para sempre lhe aureolou o nome.

Os seus dois livros "apontamentos sôbre o processo criminal brasileiro" e "apontamentos sôbre as formalidades do processo civil", que ainda hoje se consultam com proveito, assinalam o empenho de Pimenta Bueno pela boa administração da justiça e pela melhor e mais adequada sistematização do processo, cujos atos e têrmos, dizia êle, devem preencher a finalidade de proteger os litigantes, facilitando também aos juízes o conhecimento da verdade para a boa aplicação do direito.

Adrede escolhera, para marcar o pensamento orientador de seu trabalho, a frase de Faustin Hélie "les hommes ne sauraient être libres et tranquilles si la justice est mal administrée."

Preocupou-se Pimenta Bueno, principalmente, com as formas processuais, isto é, com o aspecto extrínseco do processo, fiel à lição dos praxistas, mas é de justiça salientar que êle foi além, ao precisar que "estudar as leis não é estudar apenas as suas expressões, mas sim também a sua teoria, os seus princípios, a razão, extensão e valor de seus preceitos e seu fim de pública utilidade, porque o direito funda-se na boa razão." 
Quando Paula Baptista, o notável professor de Recife, publicou, em 1855, o Compêndio de Teoria e Prática do Processo Civil, extraordinária foi a repercussão de seu trabalho, no qual, a par de seu profundo saber jurídico, se evidenciava a originalidade de seu pensamento.

No opúsculo "Paula Batista, atualidades de um velho processualista", o eminente colega, professor Alfredo Buzaid, estuda carinhosamente a obra de Paula Batista e salienta, com inteira justiça, que "a sua bagagem cientifica é realmente pequena no tamanho, porém grande no esplendor do seu gênio, na independência do seu espírito e na repercussão da sua obra, em que se revelou um precursor, que, antecipando-se aos demais quase meio século, reuniu, ordenou e sistematizou os elementos para a revisão científica do direito processual civil brasileiro."

Quanto ao Barão de Ramalho, professor da nossa Faculdade, apegado à tradição portuguêsa, revelou em seus livros a preocupação de conservar o processo, que herdáramos de Portugal, constituindo, por isso, a sua obra um repositório da lição dos praxistas, um compêndio de prática forense, que em nada contribuiria para a renovação do processo civil pátrio.

Na sua "Praxe Brasileira" e na "Prática Civil" não há pensamento filosófico e nem o recurso aos princípios que animam e informam a processualística.

Estávamos já nos fins do século 19 e ainda não saíramos dessa fase procedimentalista, que, aliás, dominava nos países latinos.

Assinala Manfredini que "o processo civil era, então, como que uma filha abandonada, uma pobre gata borralheira. . Os grandes jurisconsultos e os grandes reformadores com êle não se preocupavam, julgando-o indigno de excitar o ardor de seus generosos espíritos. Os práticos o tinham apenas como um meio de tratar das causas em juízo e de ganhar dinheiro." 
Desdenhado, relegado, assim, à condição de mero capitulo do direito civil, sem autonomia, o processo ficou ainda durante muito tempo à margem do movimento que tão alto elevou os demais ramos da ciência jurídica.

João Monteiro, que ingressara, em 1883, nesta Faculdade, após haver lecionado várias disciplinas, fôra nomeado catedrático de Processo Civil em 1896.

A sua famosa obra "Teoria do Processo Civil e Comercial", em 3 volumes, iniciada em 1899, terminara em 1901.

Embora se apoiasse na doutrina dos praxistas, uma vez que, apesar da aplicação do regulamento comercial 737 ao cível, o nosso direito civil continuava ainda a reger-se pelas vetustas Ordenações, modificadas em vários pontos pelas leis imperiais e pelas leis da nova república, João Monteiro distinguiu-se como um espírito lúcido e arejado, como um pesquisador de reais méritos, vulgarizando entre nós a melhor doutrina processual do momento, especialmente a italiana.

Dizia que o processo não pode ser considerado apenas como a forma estabelecida pela lei para as causas em juízo, como a arte das fórmulas forenses, afastado, assim, de “princípios, teorias, sistemas, induções ou deduções lógicas, dêsse sôpro coerente e definido das heterogenizações fisio-psicológicas que animam, orgânica e funcionalmente, todo e qualquer domínio da atividade social"

O processo, acrescentava, é a própria dinâmica do direito, e o direito judiciário constitui uma verdadeira ciência com princípios certos e generalizações corretas.

$\mathrm{O}$ direito judiciário é o complexo das leis e das formas segundo as quais o Poder Judiciário restabelece o equilíbrio das relações de direito violadas ou ameaçadas ou sòmente as declara de modo solene para garantí-las contra possíveis lesões futuras.

Abandonando de vez a velha tradição, dava João Monteiro um passo para a concepção publicística - que hoje 
a todos nos empolga - colocando o processo no campo do direito público.

Demonstrou, no seu Tratado, prodigiosa cultura, através da citação e da crítica dos trabalhos dos melhores processualistas de seu tempo, franceses, italianos e alguns alemães.

Não se encontra, porém, em sua obra referências ao movimento renovador que se fazia então, de modo cada vez mais acentuado, na Alemanha, movimento de largas proporções, que traria, afinal, profundas conseqüências com a modificação dos rumos da processualística civil.

Com efeito, em 1868, Oscar Bulow. com a sua famosa obra "teoria das exceções dilatórias e os pressupostos processuais", desbastara o caminho para criar a ciência do processo, que até então não passava de uma mera descrição dos fenômenos processuais.

Posteriormente, Adolf Wach publicava, em 1888, o Tratado sôbre a ação declaratória, como figura geral de tutela jurídica, repelindo o tradicional conceito do processo como contrato ou quase contrato judiciário e ensinando aquilo que já vislumbrara Hegel, e explanaram Bulow e Korrler - o processo como relação jurídica. (Chrovenda, Instituições de Direito Processual Civil, n. 17).

Colocando a ação, definitivamente, no campo do direito público, WACH ensinava que ela é - não um simples atributo do direito subjetivo individual, ou êsse próprio direito em atitude de reação contra a violação - mas um direito autonomo, de natureza exclusivamente processual, um direito subjetivo público, pertencente a qualquer indivíduo, titular de um direito material, a fim de obter do Estado que êste lhe conceda a tutela jurídica mediante uma sentença favorável.

E dentro de sua doutrina, classificava as ações, não pelo seu objeto, de acôrdo com a tradição civilística, mas atendendo apenas aos efeitos das respectivas sentenças, a saber, em ações declaratórias, constitutivas e de condenação. 
As idéias alemãs, todavia, não penetraram desde logo no meio jurídico dos países latinos, observando CARNELUTTI que os franceses, principalmente os franceses, viviam ainda na fase procedimentalista, aferrados à concepção privatística do processo, utilizando-se do método exegético, sem aprofundar o estudo da história dos institutos e sem lhes dar conveniente sistematização científica.

Verdade é que, na Itália, eminentes juristas haviam, por êsse tempo, aberto horizonte novo à processualística, mas sem chegarem pròpriamente a uma renovação completa dêste importante ramo do direito.

Antônio Castellari, por exemplo, dedicou-se a investigações históricas e Ludovico Mortara, nos seus Comentários ao Código de Processo Civil, fêz a crítica, com bastante discernimento, às teorias em vigor, planeando um novo quadro para nêle colocar em posição destacada o processo.

E Luigi Matrirolo, o autor que João Monteiro preferia, embora o seu afamado "tratado de direito judiciárjo civil italiano" constituísse, como diz Chrovenda, um tesouro de máximas judiciais, com ensinamentos práticos hàbilmente ligados à exposição doutrinária, na verdade não chegou a fazer a revisão dos institutos e nem a construir um sistema capaz de favorecer o surto da disciplina.

Deve-se, inegàvelmente, a Chiovenda, o mestre de processo civil da Universidade de Roma, através de seus sucessivos trabalhos e de seu constante e fadigoso apostolado doutrinário, a realização de monumental obra, vulgarizando a doutrina alemã, acrescendo-lhe valiosa contribuição pessoal e construindo, enfim, o sistema processual moderno, que tanta repercussão e decisiva influência teve em todos os países latinos, especialmente no Brasil.

Exatamente nessa época, com João Monteiro ainda na cátedra, exalçando-a com a sua formosa inteligência e pro- 
digiosa cultura, surgiu JoÃo MENDES JúnIoR como professor da mesma disciplina.

Bacharel pela nossa Faculdade, havia defendido, teses com grande sucesso, em 1879, para obter o grau de doutor em direito e, posteriormente, em 1889, através de brilhante concurso, fôra nomeado professor substituto.

Em 1896, afinal, fôra designado para reger a cadeira. de teoria do processo civil, comercial e criminal.

Tornou-se desde logo um vulto proeminente da Congregação, firmando-se como uma das mais altas expressões lo saber jurídico em nossa terra.

Espírito profundamente conservador, avêsso a inovaçes, que muitas vêzes, em verdade, não passam de coisas sobidas através de roupagem nova, enganando aos menos. ansados, João Mendes Júnior pôs sempre em relêvo o valor do opulento corpo de doutrinas herdado de Portugal, imprinindo brilho excepcional à sua obra, que é inconfundive que se distancia da de seus antecessores, porque nela apliqu de modo constante, sem jamais quebrar-lhe a harmoni do conjunto, os princípios filosóficos de sua preferênció os princípios aristotélico-tomistas.

Eicarou o processo, sob o ponto de vista ontológico, como ubstância, como instituição una, com caraterísticas. própria

Nãose limitou a uma sistematização processual superficial, ctdando dos institutos como se apresentavam nos têrmos $d \vDash$ leis vigentes, simplesmente descrevendo-os, nem ficou no asuísmo enfadonho da prática forense.

Tudo, ho campo por êle hábil e pacientemente explorado, tudojoi submetido a um rigoroso tratamento ciêntífico.

Que seł̧rança, que lógica, que amplitude há em tôda. a sua profuda lição!

Estabeledos os princípios, ia êle pouco a pouco tirando as conseqüên as e as conclusões, usando de linguagem precisa, evitand/expressões equívocas, afastando-se de di- 
gressões sem maior alcance, realizando, em suma, um trabalho de perfeita unidade, em que tôdas as partes acabam se entrosando naturalmente dentro do sistema idealizado.

Seguia o método dedutivo, a priori, método analítico-sintético, como êle próprio definia, que decompõe para recompor.

Afirmava que o método indutivo, a posteriori, exclusivamente sintético, porque sòmènte compõe, serve para as ciências físicas, mas não é aconselhável para as ciências morais, entre as quais se inclui o direito.

Os que se utilizam dêsse método indutivo, preocupam-se apenas com os fatos e as leis, ao passo que os seguidores do método dedutivo levam em conta, além dos fatos e das leis, as causas que produzem os fatos e os princípios que legitimam as leis.

Aplicando, assim, o método a priori, João Mendes Júnior construiu o seu sistema processual, partindo sempre dos princípios e jogando com as causas aristotélicas para chegar a conclusões certas e precisas, com admirável unidade lógica.

As três noções fundamentais, que formam o conteúdo do Direito Judiciário Civil - expressão de seu agrado, embora equivalente a Direito Processual Civil $\sim$ são a jurisdição, a ação e o processo pròpriamente diţ̣.

Como disciplina autônoma, o Direito Judiçário é o complexo dos principios e das leis que regem a atividade do Poder Judiciário e dos que a êle requerem pu perante êle litigam na administração da justiça.

É ciência e legislação, porque abrange principios e leis.

A jurisdição é a função de declarar o diretto aplicável aos fatos-causa específica da atividade do Podẹ Judiciário.

O aspecto novo da doutrina de João Mendes Júnior, que deve ser ressaltado, consistia no entrosamento que fazia entre a jurisdição e os mandamentos constitucionais. 
Já no seu "processo criminal brasileiro" havia ensinadu que "o processo criminal tem seus princípios, suas regras e suas leis; princípios consagrados nas constituições políticas, regras cientificamente deduzidas da natureza das coisas, leis formalmente dispostas para exercerem sôbre os juízes um despotismo salutar, que lhes imponha quase mecânicamente a imparcialidade. As leis do processo são o complemento necessário das leis constitucionais. As formalidades do processo são as atualidades das garantias constitucionais.. As leis do processo são regras práticas, pelas quais cada legislador buscou aplicar aos fatos e às circunstâncias os princípios constitucionais e as regras da ciência.

No "direito judiciário brasileiro" continuou a mesma lição, afirmando que "o Poder Judiciário é instituído para garantir a realização dos direitos individuais e, para isso, os respectivos órgãos devem ter jurisdição, isto é, a função de conhecer dos fatos e de dizer o direito" e que as formalidades do processo são necessárias, porque cada ato processual é um meio não só para chegar ao fim próximo, que é o julgamento, como ao fim remoto, que é a segurança constitucional dos direitos.

Vigoroso, ainda, se manifestou o gênio de João Mendes Júnior ao conceituar a ação judiciária.

Baseando-se na doutrina tomista, ensinava que a lei é substância e a ação um de seus acidentes: actio est accidens quo mediante substantia producit effectum.

Se o efeito da lei se realiza pacificamente pela manifestação da vontade individual, a ação se faz ato - ato jurídico; mas, se o efeito próprio da substância não se realiza dada a oposição da vontade individual, a lei, neste caso, tem por si um de seus acidentes, que é a ação.

Violado ou ameaçado o direito individual, a lei, na ordem social, reage pela fôrça do poder público mediante a ação judiciária. 
Daí, o texto do art. 75 do nosso cód. civil: "a todo direito corresponde uma ação que o assegura".

Para definir a ação, jogando com as quatro causas aristotélicas, João Mendes Júnior, considerou-a sob quatro aspectos.

$\mathrm{Na}$ acepção subjetiva, tendo-se em vista a causa eficiente, a ação é um atributo do sujeito, um direito do indíviduo.

Adotando a clássica definição de CELso - jus persequendi in judicio quod sibi debetur —, dizia que a ação é o direito de requerer em juízo aquilo que nos é devido.

$\mathrm{Na}$ acepção objetiva, levando-se em conta a causa final, a ação é o remédio de direito para pedir ao juiz que obrigue a outrem a dar ou fazer aquilo de que tem obrigação perfeita.

$\mathrm{Na}$ acepção material, quanto à causa material, a ação é o litígio em juízo acêrca de uma relação de direito, ou, por outras palavras, aquilo que, na linguagem vulgar, se denomina pleito ou demanda.

Finalmente, na acepção formal, tendo-se em vista a causa formal, a ação é a série ordenada e processual de atos formalizados pela lei para o litígio em juízo sôbre uma causa ou relação de direito.

Estas acepções, concluia João Mendes Júnior, são o resultado de uma abstração, importando uma distinção no conceito, mas não uma separação na coisa.

Afastava-se, assim, das definições de ação, que juristas estrangeiros e nacionais haviam oferecido, afirmando, com a autoridade que possuia, que elas não sobrepujavam a sua, pois umas eram incompletas, outras redundantes, outras não exprimiam o gênero próximo ou a diferença específica, e outras não exprimiam coisa alguma.

Quase tôdas manifestavam mais a imaginação dos definidores que a coisa definida. .

Admirável também a doutrina do mestre sôbre o processo pròpriamente dito. 
O movimento, dizia, tendente a um fim imediato, consiste em um só ato, mas quando êste fim não pode ser conseguido imediatamente, o movimento é continuado por atos intermédios que, para realizar a tendência e dirigir-se para o fim intentado, devem seguir para diante, coordenadamente, uns causando os outros.

O movimento assim dirigido chama-se processo, de pro, adiante, e cedere, ir, visto que os atos intermédios, uns causando os outros, na ordem da anterioridade e da posteridade, seguem para diante até chegar ao seu último têrmo. Processo, pois, ontològicamente, é o movimento dirigido para diante.

Assim, o processo judicial é o movimento dos atos da ação judiciária.

Todavia, acrescentava de maneira admirável, é preciso não confundir processo com procedimento, expressões que geralmente andam confundidas nos trabalhos processuais.

o processo é uma direção no movimento; o procedimento, é o modo de mover e a forma em que é movido o ato.

Em sua derivação etimológica, o sufixo mentum exprime os atos no modo de fazê-los e na forma em que são feitos.

Assim, a prática forense é um procedimento que consiste no modo de fazer e na forma em que é feito o ato forense.

O procedimento, em suma, é o movimento em sua forma extrínseca, enquanto o processo é o movimento dos atos em sua forma intrínseca.

A forma extrínseca vem acrescentar-se ao ato já constituído em sua espécie, dando-lhe, na manifestação sensivel, formas acidentais, que podem ser diferentes, sem alterar-lhe a substância.

Assim, por exemplo, a proposição da ação, a contrariedade podem ser feitas por simples exposição, ou por itens e articulados, sem que, por isso, deixe de ficar constituída 
a ação ou a contrariedade; estas e outras formas extrínsecas dos atos processuais podem ser manifestadas oralmente ou por escrito, sem que se lhes mude a substância.

Que preciosa lição, pelas importantes conseqüências que advem da necessária distinção entre processo e procedimento!

No entanto, esta distinção não é feita geralmente pelos processualistas.

Veja-se, por exemplo, entre outros, EnRico Redenti, no "profili pratici del diritto processuale civile", o qual, depois de assinalar que o vocábulo processo se usa para exprimir o fenômeno da administração da justiça, quando entra em atividade de funções a respeito dos casos concretos, desde o primeiro ato que lhe dá início até o momento em que legalmente se exaure através da sentença, ensina que, nesse sentido, também podem ser utilizadas as expressões "procedimento" e "procedura".

Chiovenda, porém, que conceitua o processo como o conjunto de atos que visam a constituição, a conservação, o desenvolvimento, a modificação ou a definição de uma relação processual, distingue o procedimento como o conjunto das atividades das partes e dos órgãos jurisdicionais mediante as quais a lide procede do princípio até o fim, e que se acham submetidas a diversas condições, denominadas formas processuais em sentido estrito.

Mais incisivo é Francesco Carneluttr, no seu "Sistema del diritto processuale civile", vol. $3 .^{\circ}$, pág. 40: "uma exigência metodológica imprescindível para o estudo do procedimento, a qual se resolve, como acontece quase sempre, numa exigência terminológica, leva-me a observar com a maior rigor possivel a distinção entre o conjunto de atos que se praticam para a composição da lide e a ordem ou sucessão dos mesmos; o primeiro destes conceitos deve ser chamado de processo e o segundo de procedimento. Embora seja tênue, para não dizer capilar, a diferença do significado dêstes dois vocábulos, e embora seja hábito 
usá-los indiferentemente, chamo a atenção dos estudiosos para considerar essa distinção, sem a qual quase impossível será pôr ordem no conjunto dos fenômenos, que a teoria do procedimento ensina a conhecer."

Vê-se, pois, que, nos princípios do século, João Mendes Júnior distinguia o processo do procedimento, lição repetida, cinqüenta anos depois por Chiovenda e Carnelutti.

Uma vez que o processo se exerce pelo procedimento na instância, João Mendes Júnior, dentro, como sempre, da sua escola, utilizando-se da linguagem filosófica apropriada, ensinava que a instância é a existência fluente do mesmo móvel no curso do movimento.

Por outras palavras, é o juízo enquanto se the expõe o pedido e a contestação, enquanto se lhe levam os instrumentos da postulação e os probatórios, e enquanto se julga a mesma causa.

Há instância enquanto existe o litígio em juízo.

Hoje, vai predominando entre os processualistas a opinião de que a instância é uma relação jurídica, que se forma entre o autor e o réu e entre êles e o juiz, como representante do Estado.

Instância e relação processual são, portanto, têrmos sinônimos.

A instância, como ensinava João Mendes Júnior, tem aspecto dinâmico e esta é exatamente uma das caraterísticas da relação processual, a qual, diferentemente das demais relações jurídicas, uma vez formada, não se estabiliza, mas transforma-se e vai evoluindo até a formação da coisa julgada.

Ai ficam, resumidamente, os aspectos mais importantes. da grande obra processual do exímio mestre, que foi João. Mendes Júnior.

Impossível seria, evidentemente, estudá-la em suas minúcias, através de uma simples conferência, mas, ainda 
assim, procuramos ressaltar-lhe a unidade, a harmonia e a originalidade.

Embora esteja superada em alguns pontos pelos modernos trabalhos de eminentes processualistas, a obra científica de João Mendes Júnior permanece íntegra, digna de emparelhar-se às melhores escritas em outros idiomas.

A sua influência, como bem assinalou Manuel Carlos de Figueiredo Ferraz (apontamentos sôbre a noção ontológica do processo), está destinada a crescer no espírito das novas gerações. O tempo emudece muitos ecos da trombeta da fama, mas perpetua e nimba de um brilho redobrado o nome dêsses homens raros, cuja obra tem o condão de imprimir novas fôrças ao pensamento.

De João Mendes Júnior disse o saudoso professo ReINaldo Porchart que era "o tipo mais completo de jurisconsulto que passou pela Congregação da Faculdade de Direito, porque, ao lado de seus profundos conhecimentos jurídicos, era um verdadeiro filósofo, fundando sempre a sua doutrina nas claras noções das coisas, dos princípios e das causas, de acôrdo com Aristóteles, de quem fôra fiel e brilhantíssimo discípulo."

E outro eminente professor desta Faculdade Francisco Morato, o seu substituto na cátedra, por ocasião da sessão solene da Congregação, consagradai à memória de João Mendes Júnior, salientou que "o exímio processualista foi insigne na ciência, insigne no caráter e insigne na modéstia. $\mathrm{Na}$ ciência, aprofundou-se em quase todos os ramos dos conhecimentos jurídicos, sociais e filosóficos, conquistando a palma de uma das maiores cerebrações do Brasil; no caráter, tomado o têrmo como expressão de firmeza e constância na conduta e modo de agir, morreu com as idéias em que nasceu e das quais nunca se desviou, na esteira das tradições e da nobreza de sua ilustre prosápia; na modéstia, enfileirou-se entre os poucos que, penetrando a pequenineza da vida e o fundo da verdadeira sabedoria, se deixam perfumar do sôpro da santidade." 
$\mathrm{Na}$ época confusa em que vivemos, batida de pruridos iconoclastas, é dever nosso - entre o que nos vem do passado e o que nos espera no futuro - defender o opulento corpo de doutrinas que nos legaram os nossos maiores, afeiçoando-as às necessidades do pensamento moderno e concorrendo, com o nosso esfôrço, a nossa dedicação, e, principalmente, com alto sentimento de brasilidade, para que mais se aperfeiçoe o direito nacional.

A fôrça da tradição - a grande fôrça desta Casa mais que centenária, fôrça invisível, mas poderosa, nos levará certamente a cultuar sempre, com carinho e desvêlo, o seu renome e o seu passado de glórias. 